\title{
Mechanical Characteristics of Red Sandstone Under Cyclic Wetting and Drying
}

\author{
Zhao Baoyun $^{1} \cdot \operatorname{Li}$ Yongfei $^{1} \cdot$ Huang Wei $^{1} \cdot$ Zhang Liyun $^{1} \cdot$ Li Wangcheng $^{1} \cdot$ Zhang $\mathbf{L i}^{1}$
}

\begin{abstract}
The bank slope of the Three Gorges Reservoir is affected by seasonal water level fluctuations, which leads to deterioration of the rock mass, resulting in a series of geological disasters such as landslides and mudslides. Therefore, in order to thoroughly understand the degradation mechanism of mechanical characteristics under wetting-drying cycles, uniaxial compression tests and triaxial compression tests were used to reveal the relationship between mechanical characteristics and wetting-drying cycles. Uniaxial compression tests results show that with the number of wetting-drying cycles increases, the mechanical characteristics show a decreasing trend, and the compaction stage of the sample increases significantly. It was found that the first 10 wetting-drying cycles have a greater impact on the mechanical characteristics of red sandstone under the triaxial compression condition, the mechanical parameters such as deviatoric stress, elasticity modulus dropped rapidly under the first 10 cycles and then tend to be stable. Based on the testing data under wetting-drying cycle condition, the mechanical parameters of the statistics damage constitutive model were modified and the results show that the modified damage constitutive model has a high degree of fit with the test data, indicating that the modified mechanical parameters can better reflect the degradation of red sandstone after the wetting-drying cycles. This understanding of the degradation process of the mechanical characteristics under wetting-drying cycles can provide theoretical guidance for the protection of dangerous slopes in the drawdown zone of the Three Gorges Reservoir.
\end{abstract}

Keywords: red sandstone; mechanical characteristics; wetting-drying cycles; mechanical parameters; damage constitutive model

\section{Introduction}

Red sandstone is an important component of the bank slope in the Three Gorges reservoir area. However, due to seasonal variations in reservoir water level and rainfall, red sandstone often suffers cyclic wetting-drying cycles. The rock mechanical characteristics are highly susceptible to deteriorate under the influence of cyclic wetting-drying, which is the cause of many engineering disasters (Pudlo et al.
2012; Zhao et al. 2017; Aytekin and Akcanca 2014; Tang et al. 2019; Whiteley et al. 2019). Therefore, understanding the mechanical behavior of rock subjected to cyclic wetting-drying is clearly important.

A considerable number of researches have been carried out during the past dozen years to investigate the water-weakening effect on the mechanical characteristics of different types of rock. Colb et al. (1965) conducted comparative experiments on rocks with different water content and found that the

\footnotetext{
$\triangle$ Zhao Baoyun baoyun666@cqust.edu.cn

${ }^{1}$ School of Civil Engineering and Architecture, Chongqing University of Science and Technology, Chongqing 401331, China
} 
saturated state is only about half of the dry state. Wasantha and Ranjitha (2014) carried out triaxial compression tests on rocks in different dry and wet conditions under different confining pressures, and found that under the same confining pressure, the influence of water degradation caused the peak strength to be reduced. Fu et al. (2009) carried out uniaxial compression tests on rocks after different wetting-drying cycles, and found that the deterioration was more obvious at the beginning of the cycles and weakened at the later stage. Based on the energy dissipation theory, Chen et al. (2019) reported that the rock dissipation energy increases gradually as the number of wetting-drying cycles increases. Furthermore, wetting-drying cycles cause irreversible damage to the rock internal structure. Based on the generalized strain equivalent principle and the statistical microscopic damage mechanics theory. Li et al. (2019) established damage constitutive model of rock under the effect of water-weakening and uniaxial loading.

In addition to the mechanical behavior of rocks under uniaxial and triaxial conditions, substantial research efforts have recently been focusing on the interaction of water and rock on mechanical characteristics under tensile conditions. Researchers conducted Brazilian splitting tests on rock samples under different wetting-drying conditions and obtained different findings. Liu et al. (2016) found that with the increase of the wetting-drying cycles, the longitudinal wave velocity and rebound strength of sandstone are linearly decreased. Zhao et al. (2016) conducted Brazilian splitting tests on sandstone with different cycles and found that the tensile strength can be significantly lowered by wetting, but the reduction in tensile strength is probably not sensitive to the number of wetting-drying cycles. Hua et al. (2015, 2016) found that sandstone becomes softer and ductile after cyclic wetting and drying, and the failure characteristics change from brittleness to ductility, especially when the number of wetting and drying cycles is large. Furthermore, the fracture toughness of pure mode II is more sensitive to the effects of cyclic wetting and drying than pure mode I. Guo et al. (2021) found that the crack initiation and penetration time were prolonged as the number of wetting-drying cycles increased, which indicated that the wettingdrying cycles weaken the stiffness of the rock and enhance the ductility of sandstone.

In the process of geotechnical engineering construction, it is inevitable to encounter the complex geological environment. Therefore, many researchers have carried out experimental on the damage and degradation characteristics of rocks under different geological environments. The establishment of a constitutive model that can simulate the whole process of rock stress-strain has always been a hot research topic. Wang et al. (2013) thoroughly discussed the whole process of rock deformation, introduced the statistical damage theory and considered the damage threshold, and established a damage model based on volumetric strain and post-peak residual strength. Based on the relationship between the peak stress and peak strain in the rock triaxial test, Cao et al. (2016) established a statistical damage constitutive model that can reflect the rock deformation under different confining pressures. In order to describe the brittle failure process of rocks, Renani et al. (2018) conducted uniaxial and triaxial compression experiments on granite and limestone. Based on the experimental results, a nonlinear Cohesion Weakening Friction Strengthening (CWFS) model was proposed, and this model has sufficient versatility. Regarding the influence of freeze-thaw process on the mechanical characteristics of rocks, $\mathrm{Mu}$ et al. (2017) conducted direct shear tests on jointed rocks after freeze-thaw cycles. Based on the theory of damage mechanics, the damage state variable was redefined to develop an exponential decay model of freeze-thaw cycles. The wetting-drying cycle effect of rock is a damage effect accumulated under repeated action for a long time. Kachanov (1999) proposed the concept of continuity $(\varphi)$ to reflect the deterioration mechanism of the rock. The influence of wetting-drying cycles on the strength of red sandstone was investigated by Liu et al. (2019) pointing out that the peak strength dropped sharply and tended to a certain value. Furthermore, based on the thermodynamics and the principle of energy dissipation, the damage evolution equations of red sandstone under different cycles wetting-drying are 
established.

Above researchers have carried out studies on the mechanical characteristics of different rock masses under different geological environmental conditions. This study will deeply consider the influence of confining pressure and wetting-drying cycles on the strength characteristics of red sandstone. Based on the strength and deformation characteristics obtained from the test, combined with the damage and deformation theory, a damage constitutive model that can reflect the wetting-drying cycle is established. It provides theoretical support for the deterioration mechanism of sandstone slope under the wetting-drying cycles.

\section{Experimental Method}

\subsection{Sample Preparation}

The red sandstone samples were collected from the slope of the Three Gorges Reservoir water levelfluctuating zone in Chongqing, China. According to the Chinese National Standard of Regulation for testing the physical and mechanical characteristics of rock (DZ/T 0276.1-2015), the samples were cut into a cylinder of $100 \mathrm{~mm}$ in height and $50 \mathrm{~mm}$ in diameter. The parallelism error of the sample ends is within \pm $0.02 \mathrm{~mm}$, and the sample appearance is smooth without obvious cracks, as shown in Fig. 1. The samples were stored in a dry storage tank at room temperature before testing.

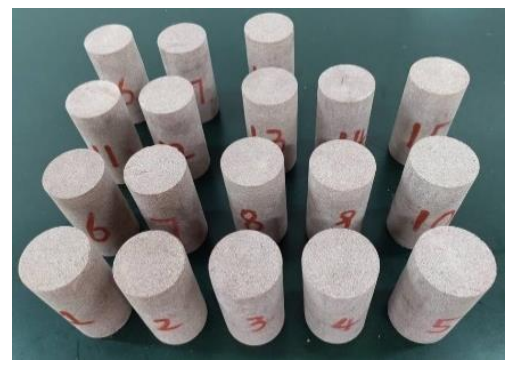

Fig. 1 Red sandstone samples

\subsection{Experimental Procedure}

The effects of wetting-drying cycles and confining pressure are considered in this test. In order to analyze the red sandstone effects under different wettingdrying cycle conditions, the samples were divided into 5 groups, the first group is natural state, and the others are the different number of wetting-drying cycles (10, 20, 30, 40). Moreover, four different confining pressure levels are set under each group $(5,10,15,20$ $\mathrm{MPa})$.

The process of the wetting-drying cycle is described as follows: 1) The height, diameter, and mass of the samples were measured and recorded. 2) According to the Chinese standard (DZ/T 0276.1$2015)$, the samples were placed in an oven at $105^{\circ} \mathrm{C}$ for $12 \mathrm{~h}$. Then, the samples were removed, cooled to ambient temperature in a desiccator, and weighed. 3) The samples were soaked in a vacuum of $100 \mathrm{kPa}$ for $12 \mathrm{~h}$ until saturation, they were removed from the water and wiped with the surface water. 4) Steps 1-3 were repeated for the next cycle until the predetermined cycle was reached, and then weighed. The process of wetting-drying cycles is shown in Fig. 2.

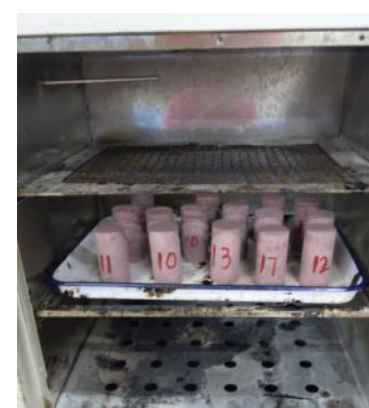

(a) Rock drying

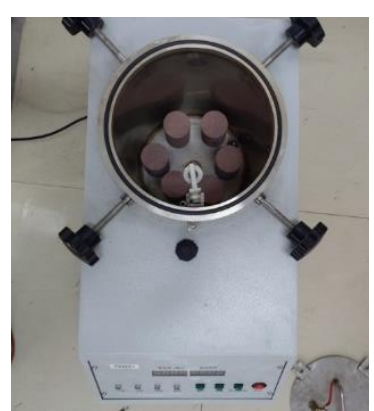

(b) Rock saturated
Fig. 2 Dryer and vacuum Saturator

\section{Deformation and failure characteristics analysis}

\subsection{Results of uniaxial compression with different wetting-drying cycles}

According to the uniaxial compression test, the mechanical parameters of the samples after different wetting-drying cycles can be obtained, as shown in Table 1. Among them, the elastic modulus is obtained from the linear fitting of the data from the approximate straight-line segment of the stress-strain curves before the peak stress. In order to explore the variation trends of the mechanical parameters after every 10 wettingdrying cycles, the stage degradation degree $(\Delta D n)$ is 
defined as the ratio of the difference between the mechanical parameters after 10 adjacent wettingdrying cycles to the original value. Then,

$\Delta D_{n}=\frac{X_{n}-X_{n+10}}{X_{n}} \times 100 \%$

$X_{n}$ is the mechanical parameter of the sample after $n$ wetting-drying cycles. Positive value of $\triangle D n$ means degradation, negative value means increase.

Table 1 Uniaxial test results under

different wetting-drying cycles

\begin{tabular}{|c|c|c|c|c|c|c|}
\hline \multirow[b]{2}{*}{$\begin{array}{c}\text { Number } \\
\text { of } \\
\text { cycles }\end{array}$} & \multirow[b]{2}{*}{$\begin{array}{c}\text { Peak axial } \\
\text { stress } \\
\sigma / \mathrm{MPa}\end{array}$} & \multirow[b]{2}{*}{$\begin{array}{c}\sigma \\
\text { deteriorat } \\
\text { ion } \\
\text { rate } / \%\end{array}$} & \multirow[b]{2}{*}{$\begin{array}{c}\text { Peak axial } \\
\text { strain } \\
\varepsilon / \%\end{array}$} & \multicolumn{3}{|c|}{ Elasti } \\
\hline & & & & $\begin{array}{c}\varepsilon \\
\text { deteriorat } \\
\text { ion } \\
\text { rate } / \%\end{array}$ & $\begin{array}{c}\mathrm{c} \\
\text { modul } \\
\text { us } \\
E \\
/ \mathrm{GPa} \\
\end{array}$ & $\begin{array}{c}E \\
\text { deteriorat } \\
\text { ion } \\
\text { rate } / \%\end{array}$ \\
\hline 0 & 76.22 & & 3.88 & & 39.19 & \\
\hline 10 & 54.23 & 28.25 & 3.67 & 5.41 & 28.12 & 28.25 \\
\hline 20 & 47.73 & 16.32 & 3.72 & -1.36 & 23.53 & 16.32 \\
\hline 30 & 44.61 & 11.26 & 4.14 & -11.29 & 20.88 & 11.26 \\
\hline 40 & 42.33 & 9.72 & 4.23 & -2.17 & 18.85 & 9.72 \\
\hline
\end{tabular}

As shown in Fig. 3, the uniaxial compression test curve under different cycles can be divided into four stages (Zhao et al. 2016). The first stage is the compaction stage (OA). The sample original cracks gradually closed under axial pressure, and the stressstrain curve shows a concave curve, and the original crack compaction time increases significantly as the number of wetting and drying cycles increases. The second stage is the linear elasticity stage $(A B)$, the sample stores energy in this stage. The slope of the curve in the elastic stage shows a decreasing trend as the wetting-drying cycles increases. The third stage is the yield stage (BC), the internal microcracks are fully developed and expanded until a connected fracture surface is formed. After the stress reaches the peak, it shows obvious brittle characteristics when the number of cycles is from 0 to 20 at the failure stage (CD). The shape of the curve shows a clear transition from brittleness to ductility, when the number of cycles increases to 30 and 40 .

It can be seen from the variation of the stage degradation degree that with the increase of the wetting-drying cycles, the peak axial strain generally shows an increasing trend, and the ductility of the sample gradually increases.

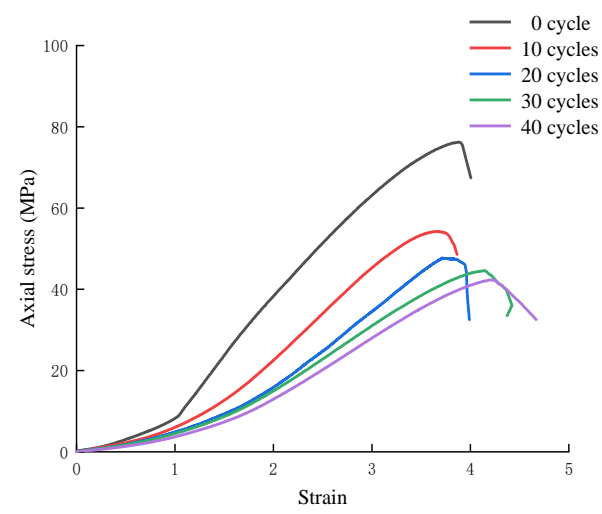

(a) Curves under different wetting-drying cycles

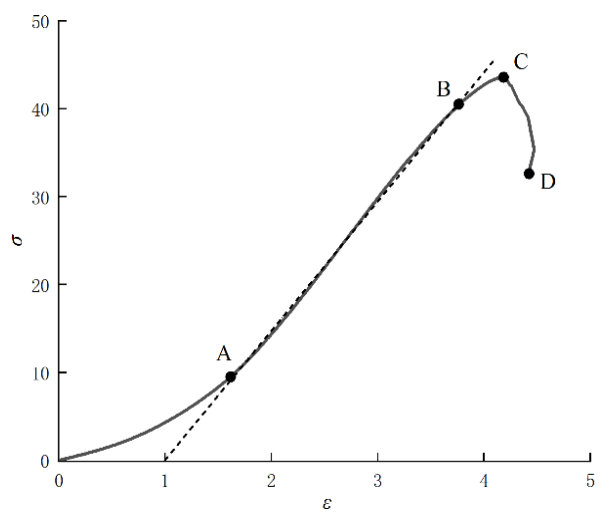

(b) Typical curve of uniaxial compression

Fig. 3 Uniaxial stress-strain curves

According to the observation of the sandstone samples after the uniaxial compression test, it is found that the sample is a typical splitting failure in the natural state, accompanied by several tensile cracks which are penetrating the sample, as shown in Fig. 4. As the number of wetting-drying cycles increases, shear cracks gradually appear around the main crack. Furthermore, the angle between the main crack and the longitudinal axis gradually increases. The failure mode of the sample is still splitting failure as a whole, but it shows a tendency of weakening brittleness and increasing ductility. After 10 wetting-drying cycles of the sample, the sandstone particles exfoliated to varying degrees around the main crack, indicating that the wetting-drying cycles have a significant degradation effect on the red sandstone samples. 


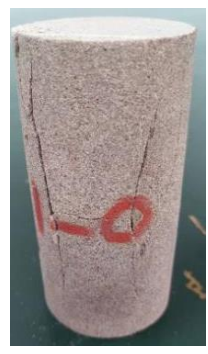

(a) 0 cycle

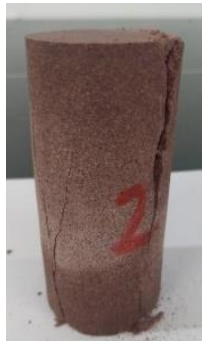

(a) 10 cycles

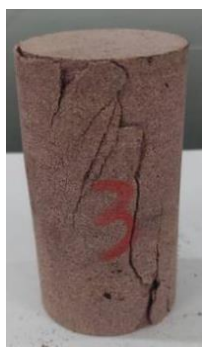

(a) 20 cycles

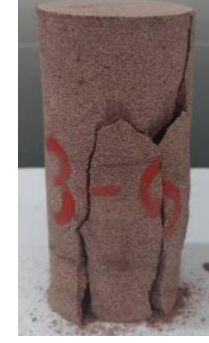

(a) 30 cycles

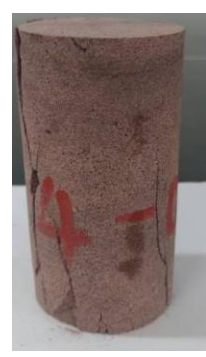

(a) 40 cycles

Fig. 4 Failure modes of sandstone under different wetting-drying cycles in uniaxial compression test

\subsection{Results of triaxial compression with} different wetting-drying cycles

The test scheme and results of triaxial compression are shown in Table 2. The variation trend of the axial strain under triaxial compression is consistent with that under uniaxial compression, and both show an increasing trend. Some samples show a reduction in peak strain, which is considered related to the discreteness of samples. The increase in peak strain indicates that the ductility of red sandstone is enhanced under the wetting-drying cycles.

Table 2 Triaxial test results under different wetting-drying cycles

\begin{tabular}{|c|c|c|c|c|c|c|c|}
\hline $\begin{array}{c}\text { Confining } \\
\text { pressure } \\
/ \mathrm{MPa}\end{array}$ & $\begin{array}{l}\text { Number of } \\
\text { cycles }\end{array}$ & $\begin{array}{c}\text { Peak axial } \\
\text { stress } \sigma / \mathrm{MPa}\end{array}$ & $\begin{array}{c}\sigma \text { deterioration } \\
\text { rate } 1 \%\end{array}$ & $\begin{array}{c}\text { Peak axial } \\
\text { strain } \varepsilon \\
1 \%\end{array}$ & $\begin{array}{c}\varepsilon \text { deterioration } \\
\text { rate } 1 \%\end{array}$ & $\begin{array}{c}\text { Elastic } \\
\text { modulus } E \\
\quad / \mathrm{GPa}\end{array}$ & $\begin{array}{c}E \text { deterioration } \\
\text { rate } 1 \%\end{array}$ \\
\hline \multirow{5}{*}{5} & 0 & 91.89 & & 3.73 & & 42.33 & \\
\hline & 10 & 63.83 & 30.54 & 3.93 & -5.36 & 30.55 & 27.83 \\
\hline & 20 & 56.88 & 10.89 & 4.09 & -4.07 & 25.61 & 16.20 \\
\hline & 30 & 53.52 & 5.91 & 4.41 & -7.82 & 23.27 & 9.10 \\
\hline & 40 & 51.34 & 4.07 & 5.88 & -33.33 & 21.50 & 7.61 \\
\hline \multirow{5}{*}{10} & 0 & 116.44 & & 4.33 & & 48.69 & \\
\hline & 10 & 75.83 & 34.88 & 4.51 & -4.16 & 33.87 & 30.44 \\
\hline & 20 & 68.13 & 10.15 & 4.64 & -2.88 & 28.27 & 16.53 \\
\hline & 30 & 63.72 & 6.47 & 4.73 & -1.94 & 25.19 & 10.89 \\
\hline & 40 & 61.27 & 3.84 & 5.25 & -10.99 & 23.66 & 6.07 \\
\hline \multirow{5}{*}{20} & 0 & 137.72 & & 5.13 & & 54.51 & \\
\hline & 10 & 88.62 & 35.65 & 5.39 & -5.07 & 35.53 & 34.82 \\
\hline & 20 & 78.39 & 11.54 & 5.44 & -0.93 & 30.26 & 14.83 \\
\hline & 30 & 74.27 & 5.26 & 6.14 & -12.87 & 27.33 & 9.68 \\
\hline & 40 & 72.49 & 2.40 & 6.37 & -3.75 & 25.83 & 5.49 \\
\hline \multirow{5}{*}{30} & 0 & 154.79 & & 5.07 & & 58.53 & \\
\hline & 10 & 100.50 & 35.07 & 5.84 & -15.19 & 36.49 & 37.66 \\
\hline & 20 & 87.10 & 13.33 & 6.16 & -5.48 & 31.73 & 13.04 \\
\hline & 30 & 81.46 & 6.48 & 5.77 & 6.33 & 29.04 & 8.48 \\
\hline & 40 & 78.60 & 3.51 & 5.29 & 8.32 & 27.01 & 6.99 \\
\hline
\end{tabular}

The stress-strain curve of red sandstone at different wetting-drying cycles is shown in Fig. 5. The samples follow the four typical development stages mentioned above, but the curve characteristics of each stage have obvious changes. Due to the influence of the confining pressure, the compaction stage in the curve is significantly shortened. In the case of high confining pressure and few cycles, this stage no longer exists. It shows that the confining pressure and the wetting- drying cycles have a greater impact on the compaction stage. The linear elasticity stage gradually shortens as the number of wetting-drying cycles increases. When the number of wetting-drying cycles reaches 10 times, the boundary between the linear elastic stage and the yield stage is no longer obvious, and the curves enter the yield phase earlier. Furthermore, after the first 10 wetting-drying cycles, the slope of the curve in the linear elastic stage dropped significantly, indicating 
that the wetting-drying cycle had a more obvious effect on the degradation of red sandstone in the early stage. With the increase of the number of wettingdrying cycles, the curve will have an obvious yield platform. After the peak point, the stress drop rate is significantly lower than the strain growth rate, showing obvious ductility characteristics.

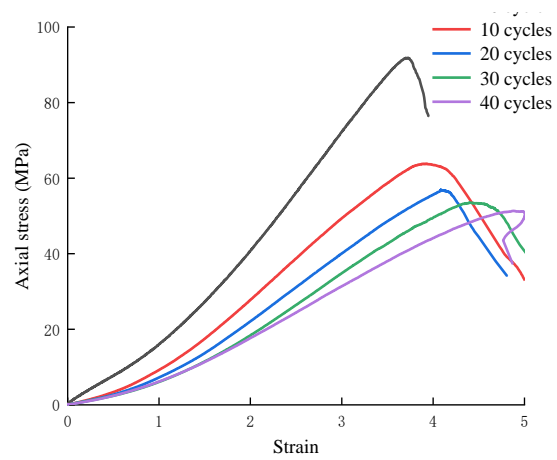

(a) $5 \mathrm{MPa}$

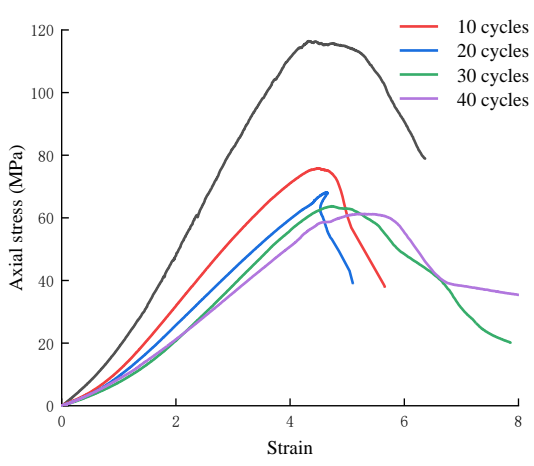

(b) $10 \mathrm{MPa}$

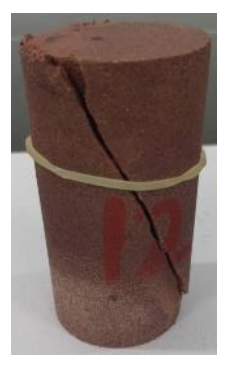

(a) 0cycle

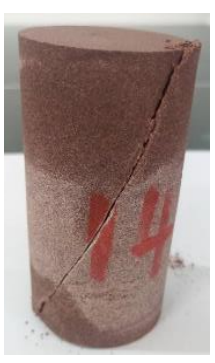

(b) 10cycles

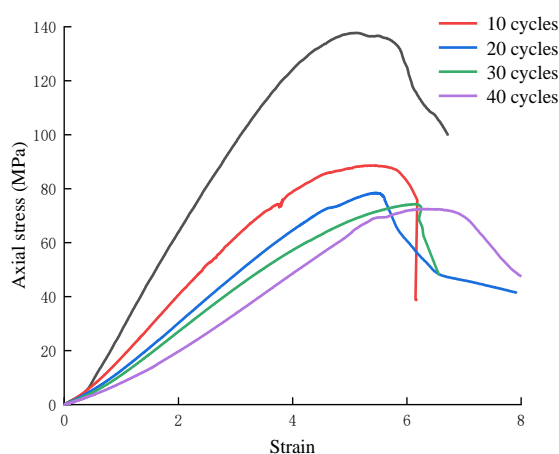

(c) $20 \mathrm{MPa}$

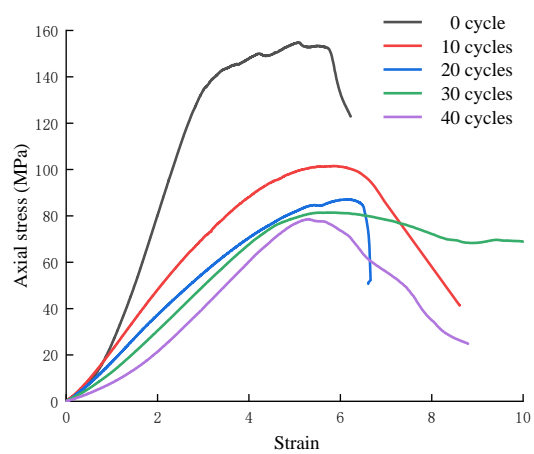

(d) $30 \mathrm{MPa}$

Fig. 5 Stress-strain curves of sandstone under different wetting-drying cycles

As shown in Fig. 6, it is a group of red sandstone failure modes at a confining pressure of $20 \mathrm{MPa}$. The samples all show obvious shear failure characteristics under the confining pressure, which is clearly different from the failure modes under uniaxial compression state.

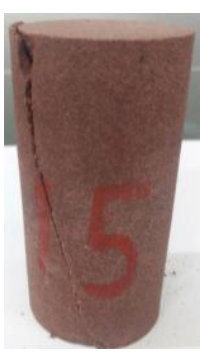

(c) 20cycles

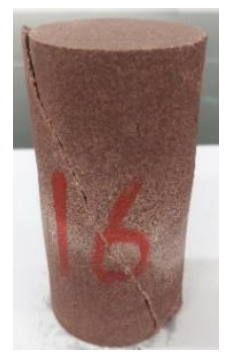

(d) 30 cycles

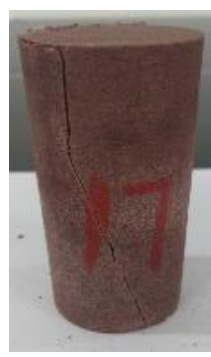

(e) 40 cycles

Fig. 6 Failure modes of sandstone under different wetting-drying cycles in $20 \mathrm{MPa}$

\section{Strength characteristics analysis}

\subsection{Peak strength and elastic modulus analysis}

The relationship between the peak stress and elastic modulus with cycle number is shown in Fig. 7.
The peak strength and elastic modulus show a significant deterioration trend. After the first 10 wetting-drying cycles, the peak strength dropped significantly, and the maximum degradation degree reached $35.65 \%$. Then, the degradation degree curves of peak strength and elastic modulus show a trend of 
slow development and leveling off as the cycles number grows from 10 to 40. In terms of the peak strength at $20 \mathrm{MPa}$, its deterioration degree decreases from $35.65 \%$ to $11.54 \%, 5.26 \%$, and $2.40 \%$, respectively, with the increase of cycle number from 0 to $10,20,30$, and 40 . The same rule applies to the

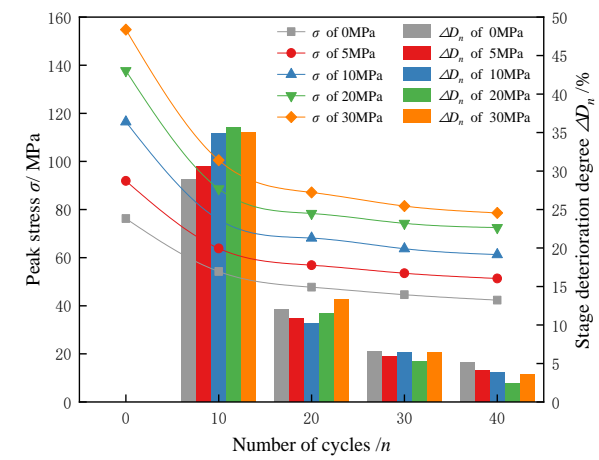

(a) Peak stress and its stage deterioration degree elastic modulus. That is, its deterioration degree decreases from $34.82 \%$ to $14.83 \%, 9.68 \%$ and $5.49 \%$, respectively, with the increase of cycle number from 0 to $10,20,30$, and 40 . The first 10 wetting-drying cycles play the biggest role in the deterioration of peak strength and elastic modulus.

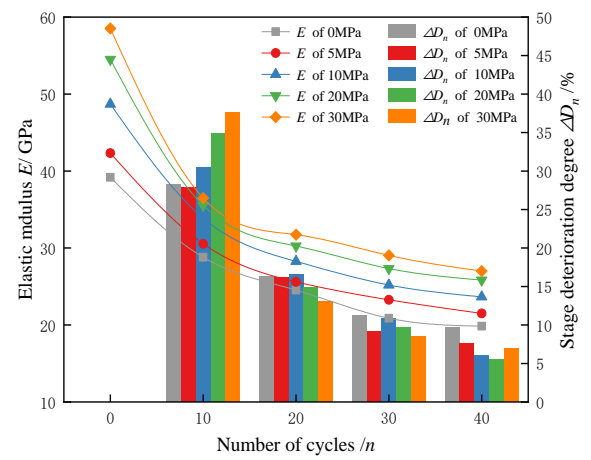

(b) Elastic modulus and its stage deterioration degree

Fig. 7 Variation trends of peak stress $\sigma$, elastic modulus $E$, and their stage deterioration degree after different wetting-drying cycles

As shown in Table 2 and Fig. 7, the peak axial stress and elastic modulus exhibit a reasonable logarithmic correlation with the cycle number. Therefore, the relationship can be expressed as:

$\sigma=A \ln \left(n^{B}+1\right)+D$

$$
E=M \ln \left(n^{P}+1\right)+Q
$$

where $n$ is the cycle number, $R^{2}$ is the square of correlation coefficient, $A, B, D, M, P$ and $Q$ are the coefficients related to the cycle number, and the values of each coefficient were obtained by a fitting analysis (as shown in Table 3 and Fig. 7).

Table 3 Fitting parameters of $\sigma$ and $\mathrm{E}$ under different conditions

\begin{tabular}{ccccccccc}
\hline $\begin{array}{c}\text { Confining } \\
\text { pressure/MPa }\end{array}$ & $\mathrm{A}$ & $\mathrm{B}$ & $\mathrm{D}$ & $\begin{array}{c}\mathrm{R}_{\sigma}^{2} \\
\left(10^{-2}\right)\end{array}$ & $\mathrm{M}$ & $\mathrm{P}$ & $\mathrm{Q}$ \\
\hline 0 & -9.74 & 0.94 & 76.21 & 99.96 & -0.05 & 116.20 & 39.61 \\
$\left(10^{-2}\right)$ & 99.30 \\
5 & -17.63 & 0.60 & 91.89 & 99.95 & -0.34 & 16.77 & 42.64 \\
20 & -31.03 & 0.44 & 116.44 & 99.98 & -0.17 & 40.83 & 48.91 & 99.62 \\
30 & -40.59 & 0.38 & 137.72 & 99.85 & -9.34 & 0.83 & 54.50 & 99.81 \\
& -38.17 & 0.51 & 154.78 & 99.85 & -14.30 & 0.57 & 58.53 \\
\hline
\end{tabular}

In order to describe the impact of wetting-drying cycles on the degree of degradation, the mass changes after different wetting-drying cycles are introduced into the analysis. It is found that the mass after wetting-drying cycle is consistent with the deterioration trend of peak strength, as shown in Fig. 8. After the first 10 wetting-drying cycles, the mass of the sample decreases greatly, but in the subsequent wetting-drying cycles, the rate of mass decreases tends to stabilize. The reason for the analysis is that during the first full saturation process, the microcracks in the sample were completely saturated with water, and the muddy impurities in the original cracks were dissolved in water, which causes the mass of the sample to rise rapidly. In the first 10 drying processes, the microcracks quickly closed under high temperature, and the moisture was accompanied by the loss of some muddy impurities, resulting in a rapid decrease in the mass of the sample. The original cracks formed a stable whole during the first 10 wetting-drying cycles. The generation of new cracks requires a long-term degradation of water resources, so there will be no 
large fluctuations in the mass of the samples during the subsequent wetting-drying cycles.

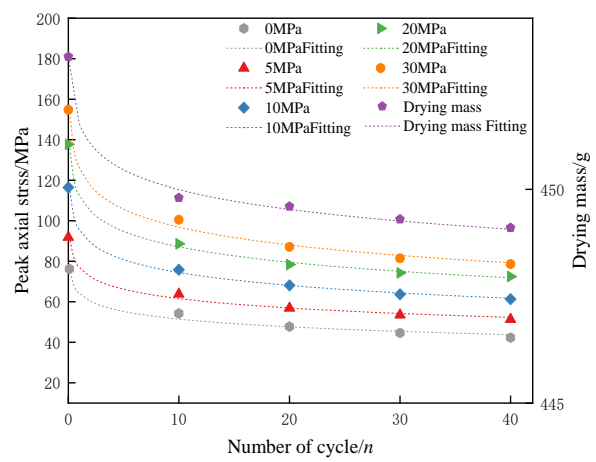

Fig. 8 Variation of sandstone peak stress with wettingdrying cycles under different confining pressure and its fitting curve

\subsection{Cohesion and internal friction angle analysis}

According to the triaxial compressive strength test results and the Mohr-Coulomb criterion, the sample cohesion and internal friction angle under different cycles can be calculated. Moreover, the rock failure can be expressed by the Mohr envelope line. If the Mohr stress circle touches the envelope line, the failure will occur.

The Mohr-Coulomb failure criterion, Eq. (4), consists of four parameters:

$$
\tau=c+\sigma \tan \varphi
$$

where $\tau$ is the shear strength, $c$ is the cohesion, $\sigma$ is the normal stress, and $\varphi$ is the internal friction angle.

When the Mohr stress circle is tangent to the strength envelope line, the relationship between the parameters can be described as Eq. (5):

$\sin \varphi=\frac{\sigma_{1}-\sigma_{3}}{\sigma_{1}+\sigma_{3}+2 c \tan \varphi}$

where $\sigma_{l}$ and $\sigma_{3}$ are the major and minor effective principal stresses at failure, respectively.

The function for judging the sample damage is Eq. (6),

$$
\sin \varphi \leq \frac{\sigma_{1}-\sigma_{3}}{\sigma_{1}+\sigma_{3}+2 c \tan \varphi}
$$

Table 2 lists the results of red sandstone under different wetting-drying cycles. Based on the MohrCoulomb criterion, the cohesion and internal friction angle can be calculated.

The triaxial compression tests were carried out on the red sandstone samples that have undergone different wetting-drying cycles, and combined with the Mohr-Coulomb strength criterion, the cohesive force $(C)$ and the internal friction angle $(\varphi)$ can be calculated under the different wetting-drying cycles, as listed in Table 4.

\begin{tabular}{ccccc}
\multicolumn{4}{c}{ Table 4 Mechanical parameters deterioration analysis } \\
\hline $\begin{array}{c}\text { Number of } \\
\text { cycles }\end{array}$ & $\begin{array}{c}\text { Cohesion } \\
\text { C/MPa }\end{array}$ & $\begin{array}{c}C \\
\text { deterioration } \\
\text { rate } / \%\end{array}$ & $\begin{array}{c}\text { Internal } \\
\text { friction angle } \\
\text { / }^{\circ}\end{array}$ & $\begin{array}{c}\varphi \\
\text { deterioration } \\
\text { rate } / \%\end{array}$ \\
\hline 0 & 24.50 & & 34.54 & \\
10 & 20.03 & 18.24 & 25.56 & 26.00 \\
20 & 18.42 & 8.04 & 22.28 & 12.83 \\
30 & 17.38 & 5.65 & 21.19 & 4.89 \\
40 & 16.57 & 4.66 & 20.53 & 3.11 \\
\hline
\end{tabular}

As shown in Fig. 9, it is easy to see that the larger number of wetting-drying cycles is, the smaller the cohesion $c$ and the internal friction angle $\varphi$ of the samples. When the number of wetting-drying cycles is 10 , the stage degradation degree of $C$ is $18.24 \%$, and the stage degradation degree of $\varphi$ is $26.00 \%$, both of which are significantly larger than the other stage degradation degrees. The variation trend of $C, \varphi$ is consistent with the change of mass, peak strength and elastic modulus. This is when the wetting-drying cycle shows its greatest effect on the $C$ and $\varphi$ of red sandstone. As the number of wetting-drying cycles increases from 10 to 40 , the influence of wettingdrying cycles is less strong, and the values of $C$ and $\varphi$ tend to decrease slowly.

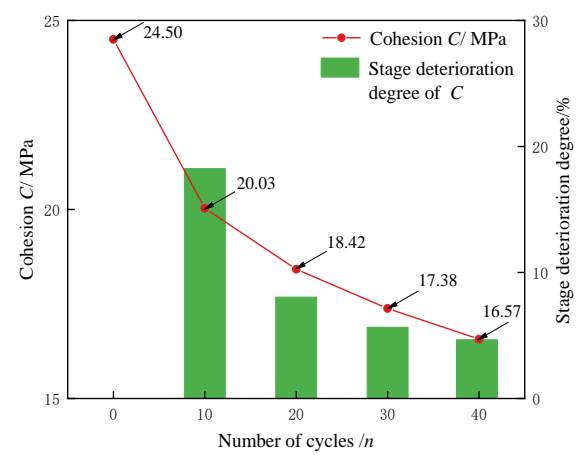

(a) Cohesion stress and its stage deterioration degree 


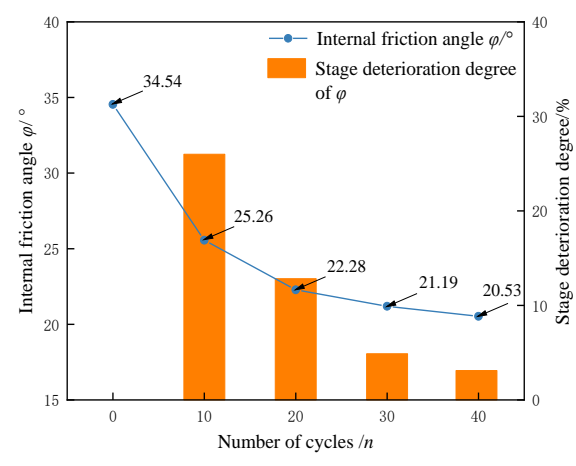

(b) Internal friction angle and its stage deterioration degree

Fig. 9 Variation trends of Cohesion $C$, Internal friction angle $\varphi$, and their stage deterioration degree after different wetting-drying cycles

The relationship between $C$ and the number of wetting-drying cycles $n$ is:

$C=-0.01 \ln \left(n^{192.15}+1\right)+24.63$

The relationship between $\varphi$ and the number of wetting-drying cycles $n$ is:

$\varphi=-3.48 \ln \left(n^{1.11}+1\right)+34.52$

\section{Deterioration mechanism analysis}

Due to the heterogeneity of the rock, it may have many weak links with different strengths. Randomly take a micro-element from the rock sample during the loading process, and the strength of each microelement is different. Tang et al. (1997) and Krajcinovic et al. (1984) established a distribution function suitable for describing the stress distribution of rock brittle fracture based on elementary statistical theory and a simple distribution law, namely Weibull distribution.

Krajcinovic and Manuel (1982) combined the continuous damage theory with the statistical strength theory and proposed a statistical damage model, as shown in Eq. (9):

$\sigma=E(1-D) \varepsilon$

In which $\sigma$ is the stress of the compression test, $\varepsilon$ is the strain of the compression test, $E$ is the elastic modulus and $D$ is the damage variable. Rock microelement strength is the key to determining damage variables. Based on the Mohr-Coulomb criterion, Cao et al. (1998) established the strength of the rock microelement $(F)$ and assumed that the strength obeys the Weibull distribution, and obtained the rock degradation constitutive equation,

$$
\begin{aligned}
& F=\frac{E \varepsilon_{1}\left[\left(\sigma_{1}-\sigma_{3}\right)-\left(\sigma_{1}+\sigma_{3}\right) \sin \varphi\right]}{\sigma_{1}-2 \mu \sigma_{3}} \\
& P(\varepsilon)=\frac{m}{F_{0}}\left(\frac{F}{F_{0}}\right)^{m-1} \exp \left[-\left(\frac{F}{F_{0}}\right)^{m}\right]
\end{aligned}
$$

where $F_{0}$ and $m$ are the mechanical parameters of the rock under the wetting-drying cycle.

The key to the establishment of the rock damage constitutive equation lies in the determination of the Weibull distribution parameters $m$ and $F_{0}$ (Cao et al. 2004). The physical meaning of the parameter $m$ is an index reflecting the brittleness of rock. The higher the value of $m$, the greater the brittleness of the rock. The physical meaning of the parameter $F_{0}$ is an index that characterizes the macroscopic average strength of the rock (Wu and Zhang 1996). The damage variable (D) of the rock material is caused by the destruction of these microelements (Cao et al. 1998; Cao et al. 2004). This equation is shown as Eq. (12).

$$
D=\int_{-\infty}^{F} P(\varepsilon) d_{\varepsilon}=1-\exp \left[-\left(\frac{F}{F_{0}}\right)^{m}\right]
$$

Substituting Eq. (12) into Eq. (9) yields the stress equation,

$\sigma=E \varepsilon \exp \left[-\left(\frac{F}{F_{0}}\right)^{m}\right]+2 \mu \sigma_{3}$

Taking the logarithm on both sides of Eq. (13),

$m\left[\ln (F)-\ln \left(F_{0}\right)\right]=\ln \left(-\ln \frac{\sigma_{1}-2 \mu \sigma_{3}}{E_{n} \varepsilon_{1}}\right)$

Assuming

that

$Y=\ln \left(-\ln \frac{\sigma_{1}-2 \mu \sigma_{3}}{E_{n} \varepsilon_{1}}\right), X=\ln (F), b=-m \ln \left(F_{0}\right) \quad, \quad$ Eq.

(14) can be rewritten as Eq. (15):

$Y=m X+b$

Based on Eq. (15), the test data under different wetting-drying cycles and confining pressures are linearly fitted, and the results of mechanical parameters $m$ and $F_{0}$ are shown in Table 5. The mechanical parameters $m$ and $F_{0}$ both show a decreasing trend with the number of cycles increases. 
Table 5 Results of $m$ and $F_{0}$ under different conditions

\begin{tabular}{|c|c|c|c|c|c|c|}
\hline \multirow{2}{*}{$\begin{array}{c}\text { Confining } \\
\text { pressure } / \mathrm{MPa}\end{array}$} & \multirow{2}{*}{$\begin{array}{l}\text { Mechanical } \\
\text { parameters }\end{array}$} & \multicolumn{5}{|c|}{ Number of cycles $/ n$} \\
\hline & & 0 & 10 & 20 & 30 & 40 \\
\hline \multirow{2}{*}{0} & $m$ & 22.42 & 16.39 & 13.72 & 11.89 & 11.06 \\
\hline & $F_{0}$ & 1.40 & 1.37 & 1.34 & 1.35 & 1.29 \\
\hline \multirow{2}{*}{5} & $m$ & 25.66 & 17.87 & 14.94 & 12.88 & 11.46 \\
\hline & $F_{0}$ & 1.31 & 1.30 & 1.29 & 1.27 & 1.21 \\
\hline \multirow{2}{*}{10} & $m$ & 26.73 & 17.90 & 15.26 & 13.23 & 12.43 \\
\hline & $F_{0}$ & 1.24 & 1.26 & 1.25 & 1.20 & 1.10 \\
\hline \multirow{2}{*}{20} & $m$ & 28.88 & 18.37 & 15.68 & 14.65 & 12.57 \\
\hline & $F_{0}$ & 1.18 & 1.15 & 1.14 & 1.06 & 0.98 \\
\hline \multirow{2}{*}{30} & $m$ & 33.24 & 19.88 & 17.16 & 17.26 & 16.05 \\
\hline & $F_{0}$ & 1.08 & 1.02 & 0.99 & 0.92 & 0.87 \\
\hline
\end{tabular}

It can be seen from Fig. 10 (a) that as the number of wetting-drying cycles increases, the parameter $m$ shows a decreasing trend as a whole, indicating that the increase of wetting-drying cycles reduces the brittleness of red sandstone. Under the same number of cycles, as the confining pressure increases, the value of $m$ increases, indicating that the red sandstone mainly undergoes brittle failure under high confining pressure. It can be seen from Fig. 10 (b) that as the number of wetting-drying cycles increases, the value of the parameter $F_{0}$ shows a decreasing trend, indicating that the wetting-drying cycle has a degrading effect on the samples. Under the same number of cycles, as the confining pressure increases, the value of $F_{0}$ decreases, indicating that the plasticity of red sandstone increases as the number of wettingdrying cycles increases.

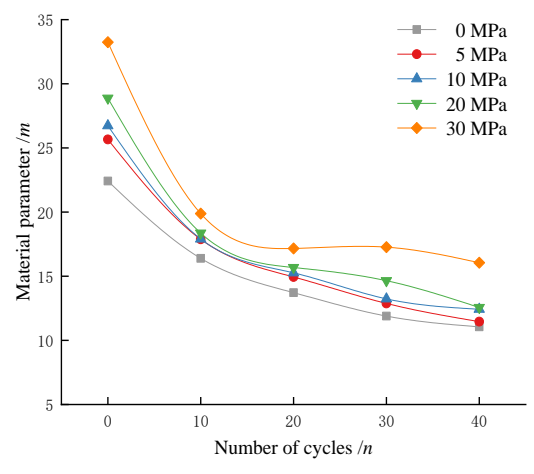

(a) Relation between the parameter $m$ and $n$

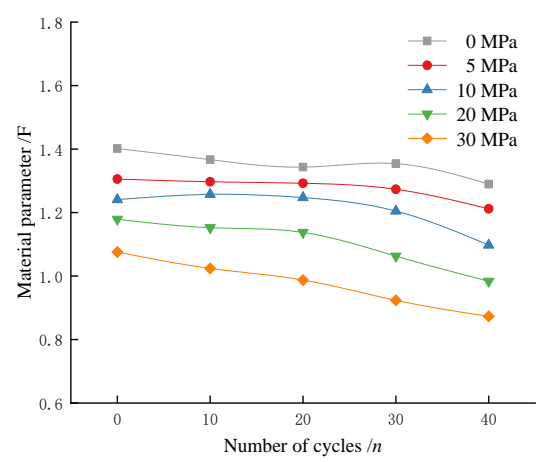

(b) Relation between the parameter $F$ and $n$

Fig. 10 Physical parameters $m$ and $F$ of red sandstone under different wetting-drying cycles

where $n$ is the cycle number, $R^{2}$ is the square of the

It can be seen from Table 5 and Fig. 10 that the decreasing trend of the mechanical parameter $m$ and the number of wetting-drying cycles show a logarithmic decrease trend. The relationship between the mechanical parameter $F_{0}$ and the number of wetting-drying cycles is approximately linear. Therefore, the relationship can be expressed as:

$m=\operatorname{In}\left(n^{J}+1\right)+K$

$F=L \times n+T$ correlation coefficient, $I, J, K, L$ and $T$ are the coefficients related to the cycle number, and the values of each coefficient were obtained by a fitting analysis, as listed in Table 6.

Table 6 Fitting parameters of $m$ and $F_{0}$ under different

\begin{tabular}{cccccccc}
\multicolumn{7}{c}{ confining pressures } \\
\hline $\begin{array}{c}\text { Confining } \\
\text { pressure/MPa }\end{array}$ & $\mathrm{I}$ & $\mathrm{J}$ & $\mathrm{K}$ & $\mathrm{R}_{\mathrm{m}}{ }^{2}$ & $\begin{array}{c}\mathrm{L} \\
\left(10^{-2}\right)\end{array}$ & $\mathrm{T}$ & $\mathrm{R}_{\mathrm{F}}{ }^{2}$ \\
\hline 0 & -0.16 & 18.93 & 22.71 & 0.96 & -0.24 & 1.40 & 0.84 \\
5 & -0.02 & 192.15 & 25.95 & 0.94 & -0.21 & 1.32 & 0.88 \\
10 & -0.02 & 192.15 & 26.78 & 0.99 & -0.34 & 1.28 & 0.87 \\
20 & -4.96 & 0.86 & 28.88 & 0.99 & -0.48 & 1.20 & 0.91
\end{tabular}




\begin{tabular}{cccccccc}
\hline $\begin{array}{c}\text { Confining } \\
\text { pressure/MPa }\end{array}$ & $\mathrm{I}$ & $\mathrm{J}$ & $\mathrm{K}$ & $\mathrm{R}_{\mathrm{m}}{ }^{2}$ & $\begin{array}{c}\mathrm{L} \\
\left(10^{-2}\right)\end{array}$ & $\mathrm{T}$ & $\mathrm{R}_{\mathrm{F}}{ }^{2}$ \\
\hline 30 & -12.64 & 0.29 & 33.24 & 0.99 & -0.51 & 1.08 & 0.99 \\
\hline
\end{tabular}

Substituting Eqs. (3), (16) and (17) into Eq. (13), the relationship between stress and the number of wetting-drying cycles can be obtained. Due to the limited space of the article, the test data under $30 \mathrm{MPa}$ is selected for analysis. The function of the stress and strain in wetting-drying cycles hence obtained is:

$\sigma=\left[-14.3 \ln \left(n^{0.57}+1\right)+58.53\right] \varepsilon \times$

$\exp \left[-\left(\frac{F}{-0.0051 \times n+1.08}\right)^{-12.64 \ln \left(n^{0.29}+1\right)+33.24}\right]+2 \times 30 \times \mu$

As shown in Fig. 11, in the pre-peak stage, the test curve is generally lower than the theoretical curve, because the test curve has an obvious compaction stage, and the compaction of the original cracks is not reflected in the constitutive equation. The fitting degree of the yield stage is relatively high, and there are obvious yield platforms. In the post-peak stage, the theoretical curve is consistent with the test curve and still has a certain residual strength. The theoretical curve can better fit the full stress-strain curve obtained from the test, indicating that the correction based on the mechanical parameters is reasonable.

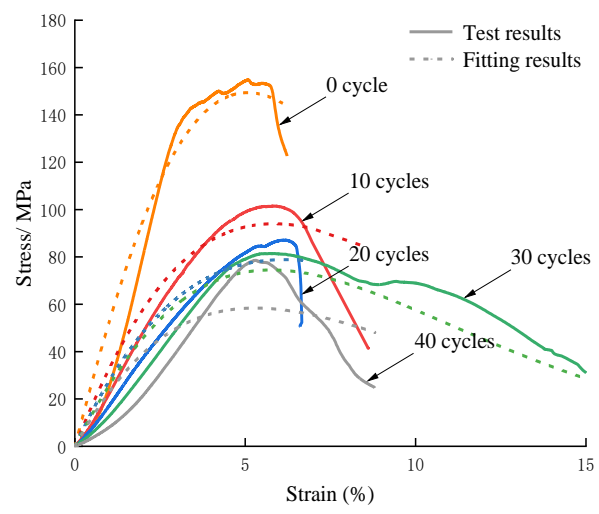

Fig. 11 Comparison between trail test $\left(\sigma_{3}=30 \mathrm{MPa}\right)$ and the model

\section{Conclusions}

In this paper, the red sandstone samples selected from the bank slope of the Three Gorges Reservoir were subjected to different wetting-drying cycles. In order to comprehensively understand its mechanical characteristics, uniaxial compression test and triaxial compression test under different confining pressure levels were carried out. Based on the test results and data analysis, the following conclusions can be drawn:

1. The mass monitoring of the red sandstone samples after the wetting-drying cycles shows that the mass of the sample changes greatly after the first 40 wetting-drying cycles. In the subsequent wettingdrying cycles, the mass changes slowly and gradually tend to a stable value.

2. The results of the uniaxial compression test of red sandstone found that with the increase of wettingdrying cycles, the peak strength and elastic modulus of the samples decreased. The failure mode of the sample is shown as a typical splitting failure.

3. Combining the results of the triaxial test and the analysis of the Mohr-Coulomb criterion, it is found that the degradation effect of wetting-drying cycles on the cohesion and internal friction angle of the red sandstone is very obvious in the first 10 cycles. As the number of wetting-drying cycles increases, the degradation effect is significantly reduced.

4. Based on the Weibull distribution characteristics of the microelement strength of the rock, the mechanical parameters of which are modified. According to the test results, the mechanical parameters of the red sandstone under the same confining pressure and after different wetting-drying cycles are obtained. Then, the test data was fitted according to the damage constitutive model, and the results showed that the theoretical curve can well fitted with the test curve, which proved that the mechanical parameters were corrected accurately.

\section{Acknowledgements}

This research was subsidized by the project of the National Natural Science Foundation of China (Grant No.41302223; Grant No.51908097), The Natural Science Foundation of Chongqing (No. cstc2020jcyjmsxm1078, No. cstc2020jcyj-msxmX0558, No. cstc2019jcyj-msxmX0258). Chongqing University of Science and Technology Graduate Students' Science and Technology Innovation Program (YKJCX 2020654, YKJCX 2020656).

\section{References}


Aytekin M, Akcanca F (2014) Impact of wetting-drying cycles on the hydraulic conductivity of liners made of lime-stabilized sand-bentonite mixtures for sanitary landfills. Environmental Earth Sciences 72(1):59-66 DOI: 10.10007/s12665-013-2936$\underline{4}$

Cao WG, Dai L, Zhang C (2016) A study of statistical damage constitutive models for deep earth rocks. Hydrogeology \& Engineering Geology 43 (4):60-65. DOI: 10.16030/j.cnki.issn. 1000-3665.2016.04.10

Cao WG, Fang ZL, Tang XJ (1998) A study of statistical constitutive model for soft and damage rocks. Chinese Journal of Rock Mechanics and Engineering, 17(6): 628-633. DOI: CNKI: SUN: YSLX.0.1998-06-003

Cao WG, Zhao MH, Liu CX (2004) Study of the model and its modifying method for rock softening and damage based on Weibull random distribution. Chinese Journal of Rock Mechanics and Engineering, 23(19): 3223-3231. DOI: 10.1007/BF02911033

Chen XX, He P, Qin Z (2019) Strength Weakening and Energy Mechanism of Rocks Subjected to Wet-Dry Cycles. Geotechnical and Geological Engineering 37(5):3915-3923. DOI: $10.1007 / \mathrm{s} 10706-019-00881-6$

Colb Ac K P, Wiid B L (1965) The influence of moisture content on the compressive strength of rocks. Proc. rock Mech. symp. Tronto.

Fu Y, Liu XR, Zhang YX, Hu YX, Xie YK (2009) Study on the influence of water-rock interaction to the strength of sandstone. Hydrogeology \& Engineering Geology 36(006):54-58. DOI: 10.3969/j.issn.1000-3665.2009.06.012

Guo P, Gu J, Yi S, Wang J, Ding Z (2021) Effect of cyclic wettingdrying on tensile mechanical behavior and microstructure of clay-bearing sandstone. International Journal of Coal Science \& Technology 1-13. DOI: 10.21203/rs.3.rs-65369/v1

Hua W, Dong S, Li Y, Xu J, Wang Q (2015) The influence of cyclic wetting and drying on the fracture toughness of sandstone. International Journal of Rock Mechanics and Mining Sciences 78:331-335. DOI: 10.1016/j.ijrmms.2015.06.010

Hua W, Dong S, Li Y (2016) Effect of cyclic wetting and drying on the pure mode II fracture toughness of sandstone. Engineering Fracture Mechanics 153:143-150. DOI: 10.1016/ j.engfracmech.2015.11.020

Kang B, Liu J, Zhang W (2019) Mechanical behavior and damage constitutive model of rock subjected to water-weakening effect and uniaxial loading. Rock Mechanics and Rock Engineering 52:97-106. DOI: 10.1007/s00603-018-1580-4

Kachanov, LM (1999). Rupture time under creep conditions. International Journal of Fracture 97(1), 11-18. DOI:10.1023/ A: 1018671022008

Krajcinovic D, Manuel AGS (1982) Statistical aspects of the continuous damage theory-ScienceDirect. International Journal of Solids and Structures 18(7), 551-562. DOI: $\underline{10.1016 / 0020-7683(82) 90039-7}$

Krajcinovic D (1984) Continuous Damage Mechanics Revisited: Basic Concepts and Definitions. Journal of Applied Mechanics 52(4): 829-834. DOI: $10.1115 / 1.3169154$

Liu S, Yang GS, Dong XH (2019) Experimental study on influence of wetting-drying cycles on mechanical characteristics and damage of red sandstone. Coal Science and Technology
47(4):101-106. DOI: CNKI: SUN: MTKJ.0.2019-04-017

Liu X, Wang Z, Yan F, Yuan W, Miao L (2016) Macro/Microtesting and Damage and Degradation of Sandstones under Dry-Wet Cycles. Advances in Materials Science and Engineering 2016:1-16. DOI: 10.1155/2016/7013032

Mu JQ, Pei XJ, Huang RQ, Rengers N, Zou XQ (2017) Degradation characteristics of shear strength of joints in three rock types due to cyclic freezing and thawing. Cold Regions Science and Technology, 138:91-97. DOI: 10.1016/j.coldregions. 2017.03.011

Pudlo D, Reitenbach V, Albrecht D, Ganzer L, Gernert U, Wienand J, Kohlhepp B, Gaupp R (2012) The impact of diagenetic fluidrock reactions on Rotliegend sandstone composition and petrophysical properties (Altmark area, central Germany). Environmental Earth Sciences 67(2):369-384. DOI: 10.1007/ s12665-012-1723-y

Renani, Hossein, Rafiei, Martin, C., Derek (2018) Cohesion degradation and friction mobilization in brittle failure of rocks. International Journal of Rock Mechanics and Mining Sciences 106:1-13. DOI: 10.1016/j.ijrmms.2018.04.003

Tang CA, Chen ZH, Xu XH, Li C (1997) A theoretical model for Kaiser effect in rock. Pure Appl. Geophys 150(1):203-215. DOI: $10.1007 / \mathrm{s} 000240050073$

Tang HM, Wasowski J, Juang CH (2019) Geohazards in the three Gorges Reservoir Area, China-Lessons learned from decades of research. Engineering Geology 261:105267-105267. DOI: 10.1016/j.enggeo.2019.105267

Wang HP, Cao WG, Wang JY, Zhang C (2013) A study of the statistical damage constitutive model of rocks considering a full deformation process. Hydrogeology \& Engineering Geology 40(4):44-49. DOI: CNKI: SUN: SWDG.0.2013-04$\underline{010}$

Wasantha PLP, Ranjitha PG (2014) Water-weakening behavior of Hawkesbury sandstone in brittle regime. Engineering Geology 178:91-101. DOI: 10.1016/j.enggeo.2014.05.015

Whiteley JS, Chambers JE, Uhlemann S, Wilkinson PB, Kendall JM (2019) Geophysical monitoring of moisture-induced landslides: a review. Reviews of Geophysics 57(1):106-145. DOI: $\underline{0.1029 / 2018 R G 000603}$

Wu Z, Zhang CJ (1996) Investigation of rock damage model and its mechanical behavior. Chinese Journal of Rock Mechanics and Engineering 15(01):55-61, DOI: CNKI: SUN: YSLX.0. 1996$\underline{01-007}$

Zhao BY, Li YF, Huang W, Wang XP, Chen C (2021) Experimental study on mechanical properties of shale rock and its strength criterion. Arabian Journal of Geosciences 14(4). DOI: 10.1007/S12517-021-06552-2

Zhao Z, Yang J, Zhou D (2017) Experimental investigation on the wetting-induced weakening of sandstone joints. Engineering Geology 225:61-67. DOI: 10.1016/j.enggeo.2017.04.008

Zhao Z, Yang J, Zhang D, Peng H (2016) Effects of Wetting and Cyclic Wetting-Drying on Tensile Strength of Sandstone with a Low Clay Mineral Content. Rock Mechanics \& Rock Engineering 50(2):1-7. DOI: 10.1007/s00603-016-1087-9

Publisher's Note Springer Nature remains neutral with regard to jurisdictional claims in published maps and institutional affiliations. 